\title{
Porcine epidemic diarrhea virus: current insights
}

\author{
This article was published in the following Dove Press journal: \\ Virus Adaptation and Treatment \\ 30 May 2016 \\ Number of times this article has been viewed
}

\section{Chaochao Lv1,* \\ Yan Xiaol,* \\ Xiangdong $\mathrm{Li}^{1}$ \\ Kegong Tian ${ }^{1,2}$}

'National Research Center for Veterinary Medicine, Luoyang, People's Republic of China; ${ }^{2}$ College of Animal Science and Veterinary Medicine, Henan Agricultural University, Zhengzhou, People's Republic of China

*These authors contributed equally to this review
Correspondence: Xiangdong Li, Kegong Tian

National Research Center for Veterinary Medicine, Road Cuiwei, High-Tech

District, Luoyang 47I 003, People's

Republic of China

$\mathrm{Tel}+861059198895$

Fax +86 I0 5919 8899

Email xiaonanzhong@।63.com; tiankg@263.net

Abstract: Porcine epidemic diarrhea virus (PEDV), an enveloped, single-stranded, positivesense RNA virus belonging to the genus Alphacoronavirus in the family Coronaviridae, can infect pigs of all ages and causes acute and watery diarrhea, vomiting, dehydration, and high mortality in neonatal piglets. This disease was first observed in England in 1971 and was subsequently reported in many swine-producing countries in Europe and Asia. In contrast to the situation in Europe, the disease has remained a major cause of diarrhea outbreaks on swine farms in Asia. Since late 2010, severe porcine epidemic diarrhea (PED) epizootics caused by new variants have been affecting pigs in the People's Republic of China, resulting in substantial economic losses. In April 2013, PEDV was identified for the first time in the United States and resulted in the estimated death of over seven million piglets during a 1-year epidemic. Nowadays, it has spread into North and South America, Asia, and Europe, causing significant economic problems worldwide. More studies have been conducted in PEDV research, and the number of scientific literatures published during the last 5 years has exceeded the total of that in the past several decades. This review focuses on the current understanding of the etiology, molecular epidemiology, transmission, diagnosis, and pathogenesis of PEDV, as well as the vaccine to prevent PEDV infection.

Keywords: PEDV, molecular epidemiology, transmission, diagnosis, pathogenesis, immune response, vaccine

\section{Introduction}

Porcine epidemic diarrhea virus (PEDV) is an enveloped, single-stranded, positive-sense RNA virus belonging to the order Nidovirale, the family Coronaviridae, subfamily Coronavirinae, and genus Alphacoronavirus. ${ }^{1}$ It can infect pigs of all ages and causes acute and watery diarrhea, vomiting, dehydration, and high mortality in neonatal piglets, resulting in significant economic losses.

The disease was initially described in the United Kingdom and Belgium in the early 1970s. The etiological agent of the disease was first isolated in 1977 in Belgium and was identified as a new coronavirus., ${ }^{2,3}$ During the 1970s and 1980s, the virus spread throughout Europe. However, during the 1980s and 1990s, the prevalence of PEDV declined markedly in Europe, and sporadic outbreaks associated with low mortality were reported only in some countries, such as the Netherlands, ${ }^{4}$ Hungary, ${ }^{5}$ and England. ${ }^{6}$ Porcine epidemic diarrhea (PED) was first reported in Asia in 1982, and since then, it has caused significant economic losses. ${ }^{7-9}$ In contrast to the situation in Europe, the disease has remained a major cause of viral diarrhea outbreaks on swine farms in Asia. Since late 2010, severe PED epizootics have been affecting pigs of all ages, 
characterized by high morbidity and mortality rates among suckling piglets in the People's Republic of China, resulting in great economic losses, although most herds previously had received CV777-based inactivated or attenuated vaccines. ${ }^{10,11}$ Phylogenetic analyses revealed that the PEDVs circulating in the People's Republic of China with higher virulence were new variants.

In April 2013, PEDV was identified for the first time in the United States; ${ }^{12}$ it spread rapidly across the country and to other countries in North and South America, including Mexico, Peru, the Dominican Republic, Canada, Colombia, and Ecuador. ${ }^{13}$ PEDV resulted in the estimated death of over seven million piglets and substantial economic losses during a 1-year epidemic. ${ }^{14}$ Recently, PED outbreaks have been reported in Germany, ${ }^{15,16}$ Italy, ${ }^{17}$ the Netherlands, ${ }^{18}$ Belgium, ${ }^{19}$ France, ${ }^{20}$ Austria, ${ }^{21}$ Portugal, ${ }^{22}$ Ukraine, ${ }^{23}$ Slovenia, ${ }^{21}$ and Hawaii. ${ }^{24,25}$

This review focuses on the current understanding of the etiology, molecular epidemiology, transmission, diagnosis, and pathogenesis of PEDV, as well as the vaccine to prevent PEDV infection.

\section{Etiology}

\section{Genome and encoding proteins}

PEDV is a large, enveloped RNA virus, with a range in diameter of 95-190 nm. ${ }^{3}$ Details of the PEDV structure can be found in Song and Park. ${ }^{26}$ The PEDV genome is approximately $28 \mathrm{~kb}$, and comprises a $5^{\prime}$ untranslated region, ORFS $1 a$ and $1 b$ encoding replicase polyproteins, spike $(S), O R F 3$, envelope $(E)$, membrane $(M)$, and nucleocapsid $(N)$ genes, and a $3^{\prime}$ untranslated region. ${ }^{27}$

PEDV possesses four structural proteins, which include three membrane proteins ( $\mathrm{S}$ protein, $\mathrm{M}$ protein, $\mathrm{E}$ protein previously called sM or small membrane protein, and $\mathrm{N}$ protein). The S protein functions as the virus attachment protein, interacting with the specific host cell receptor during virus entry; the S protein harbors neutralization epitopes related to induction of neutralizing antibodies against the virus. ${ }^{28-39}$ The $S$ protein is also associated with virus growth adaptation and attenuation in vitro and in vivo. ${ }^{40}$ In addition, the $\mathrm{S}$ protein is suitably used for molecular epidemiology analysis and vaccine development of PEDV. ${ }^{26,36,41}$ The $\mathrm{M}$ and $\mathrm{E}$ proteins play an important role in viral assembly; $M$ protein, the most abundant component among viral proteins in the envelope, is required for the assembly process by interacting with the $\mathrm{S}$ and N proteins. ${ }^{42,43}$ The $\mathrm{N}$ protein binds to the viral genome RNA and packages into the nucleocapsid of virus particles. ${ }^{44}$ The $\mathrm{N}$ protein has also been found to antagonize interferon
(IFN)- $\beta$ production as part of the immune evasion strategy of PEDV. ${ }^{45}$

PEDV has three nonstructural proteins: two encoded by ORF $1 a$ and ORF $1 b$ genes and one encoded by ORF3 gene. The accessory protein encoded by $O R F 3$ has been reported to function as an ion channel and also be related to viral virulence. ${ }^{46,47}$

\section{Cell culture for virus isolation}

Obtaining an epidemic PEDV isolate that can grow efficiently in cell culture is critical for the development of vaccines. The PEDV growth in cell culture was reported to be difficult, and the virus may gradually lose infectivity upon further passages in cell culture. ${ }^{41}$ Vero (African green monkey kidney) cells support the isolation and serial propagation of PEDV in laboratory conditions; another African green monkey kidney cell line, MARC-145, was also reported to support the cell passages of PEDV. ${ }^{48}$ However, growth of PEDV depends on the presence of trypsin supplemented in the cell culture medium. Trypsin plays an important role in cell entry and release of PEDV virions in Vero cells by cleaving the S protein into S1 and S2 subunits and enables efficient replication and spread of PEDV in vitro. ${ }^{38,49}$ Typical cytopathic effect was characterized by cell fusion and syncytium formation. . $^{1,50}$

There are previous reports of successful propagation of several classical PEDV strains using Vero cells and trypsin in the medium, such as CV777, KPEDV-9, and 83P-5. ${ }^{50-52}$ Recently, several highly virulent US PEDV strains were serially propagated in Vero cell cultures for over 30 passages. ${ }^{41,53}$ Two Chinese variants, HN1303 and YN1, have also been serially propagated in Vero cell cultures for over 130 (unpublished data) and 200 passages, respectively. ${ }^{1,54}$ Nonetheless, low success rates $(0 \%-14.3 \%)$ of virus isolation from PEDV-positive intestine samples or feces have been recently reported by some research teams. ${ }^{1,41,53}$ Multiple factors may affect the successful rate of virus isolation, such as the type of specimen, freshness, virus titer, substances in intestinal contents, strain-specific factors, Vero cell lines, and culture conditions.

\section{Molecular epidemiology PEDV genotyping}

Sequencing and genotyping based on the whole-genome or some special genes such as $S, M, N$, or $O R F 3$ genes have been carried out to determine the diversity and evolutional relationships of PEDV isolates. Among these genetic loci, the full-length $S$ gene and the $S 1$ portion have been shown to be appropriate for sequencing to study the genetic relatedness 
and molecular epidemiology of PEDV ${ }^{41,55}$ Phylogenetic analysis of the full-length $S$ gene inferred by a neighbor-joining method indicates that PEDV could be genetically divided into two groups, which include GI and GII. GI and GII can be further divided into subgroups Ia and Ib, and IIa and IIb, respectively (Figure 1). Genotype Ia contains classical strains, including the prototype strain CV777 and historical vaccine strains, and genotype Ib includes some variants such as OH851-like isolates from the People's Republic of China, the United States, South Korea, Europe, and Austria. ${ }^{16,19-21,56,57}$ Genotype II contains historical isolates in South Korea, and currently prevalent global field isolates. Genotype IIa was a recently prevalent genotype in the People's Republic of China, ${ }^{58,59}$ Taiwan, ${ }^{60-62}$ South Korea, ${ }^{55,63}$ and the United States. ${ }^{41,58}$ Genotype IIb was another prevalent genotype in the People's Republic of China, and responsible for epidemic outbreaks in Vietnam in 2013.1,41,64

Compared to the sequencing based on individual genes, whole-genome sequencing can provide more valuable information on the genetic diversity and evolution of the virus For example, evidences of recombination among the highly virulent variants, and between the highly virulent variant and vaccine strain have been recently reported..$^{65,66}$

\section{Recent molecular epidemiology (late 20 I0-present) in Asia, the Americas, Europe, and Oceania}

Details of molecular epidemiology of PEDV before 2010 can be found elsewhere. ${ }^{13,26}$

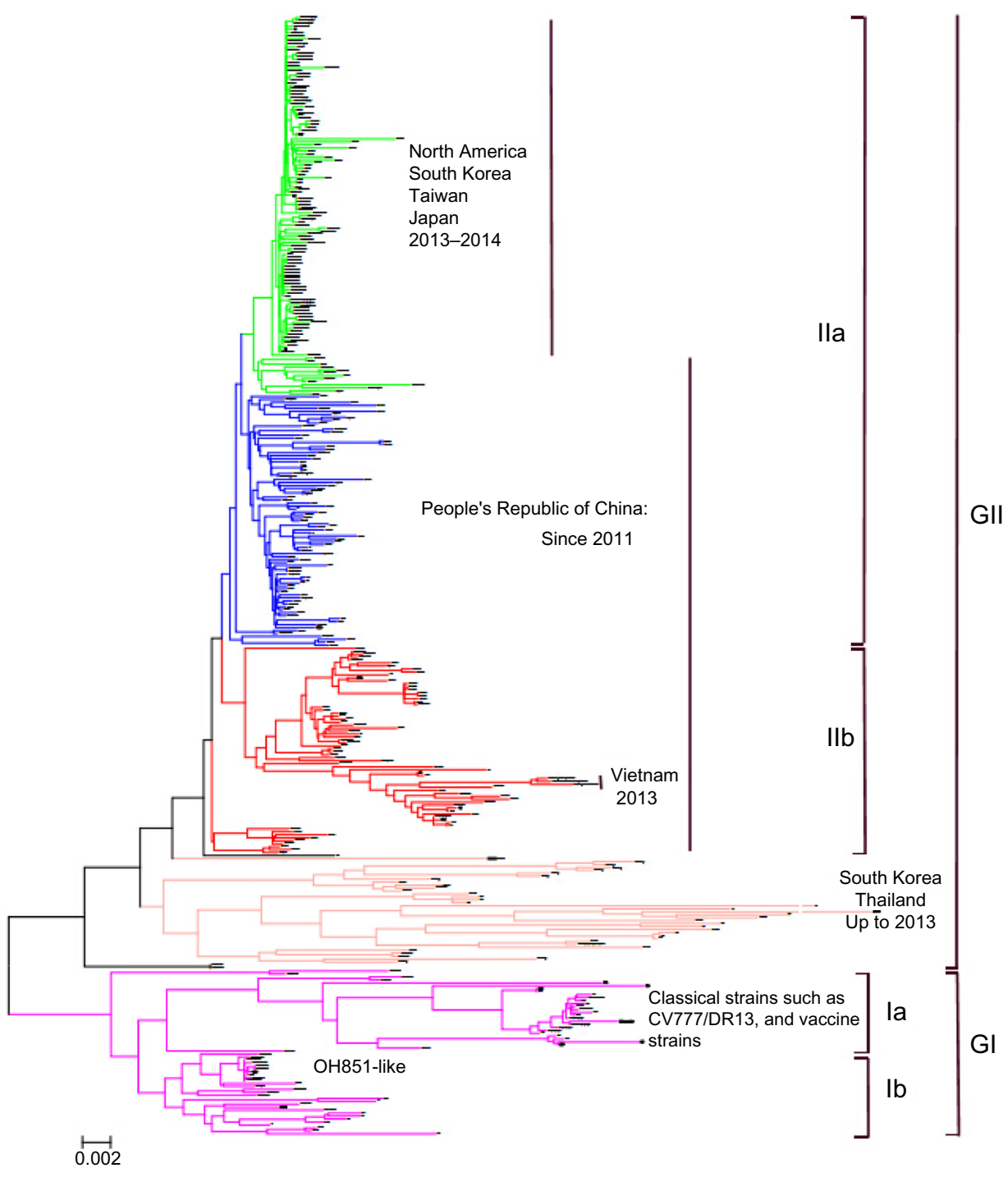

Figure I Phylogenetic analyses of worldwide PEDV strains based on the full-length $S$ gene nucleotide sequences, as inferred by a neighbor-joining analysis based on distance calculated using the Kimura 2-parameter model of software PHYLIP version 3.67.

Abbreviation: PEDV, porcine epidemic diarrhea virus. 


\section{Asia}

In October 2010, a large-scale outbreak of PEDV was reported in several provinces of the People's Republic of China and rapidly spread to other provinces. ${ }^{10,11,67}$ Although many swine herds had been vaccinated with CV777 strain-based inactivated vaccines, the outbreaks caused moderate-to-high mortality in suckling piglets. ${ }^{67}$ The results of many studies based on sequencing and phylogenetic analyses showed that these PEDV isolates with high virulence circulating in the People's Republic of China were new variants and differed genetically from the prototype CV777 strain. ${ }^{11,59,67-78}$ Now, PED became endemic; however, it remains the most devastating enteric disease leading to serious losses in the People's Republic of China. PED outbreaks in the People's Republic of China from late 2010 were caused by at least three genotypes, including genotypes IIa, IIb, and Ib. In addition, two genotype IIa strains, AH2012 (GenBank accession number KC210145) and CH/ZMDZY/11 (GenBank accession number KC196276), were thought to be potential progenitors of US PEDV strains that emerged subsequently during 2013. . $8,65^{\circ}$ One genotype Ib strain CH/HBQX/10 (GenBank accession number JX501318) was shown to be most closely related to the OH851-like strains currently circulating in the United States and Europe based on phylogenetic analysis of the full-length $S$ gene. ${ }^{57}$ Recently, a novel PEDV variant FL2013 (GenBank accession number KP765609) with reduced virulence was identified from east People's Republic of China, having a 7-aa deletion at the $\mathrm{C}$-terminus of the $\mathrm{S}$ protein. ${ }^{79}$

In 2013, three pig herds located in North and South Vietnam experienced PED outbreaks; all the PEDV isolates were identified as the genotype IIb consisted of several Chinese isolates. ${ }^{64}$

In addition, from late 2013, PEDV outbreaks were reported in Japan, South Korea, and Taiwan. ${ }^{55,60,80}$ The predominant genotypes of PEDV in these regions during 2013-2014 were all phylogenetically related to the highly pathogenic US-like lineage within the genotype IIa. ${ }^{55,60,80}$ The source of PEDV incursion into swine populations in these regions has not yet been determined. Novel variant $\mathrm{Ib}$ isolates also have been detected in South Korea and Japan during 2013-2014, which were most closely related to the US variant OH851. ${ }^{56,81}$ Another novel IIa variant Tottori2/ JPN/2014 (GenBank accession number LC022792) with a large deletion (582 nt) in the $S$ gene was detected in Japan in October 2014. ${ }^{82}$

The swine population in the Philippines suddenly suffered from typical PED in 2014, with high mortality rates. The isolates responsible for the PED outbreaks in the Philippines in 2014 were found to be most related to those genotype II strains circulating in the People's Republic of China and Vietnam on the basis of the $S$ and $O R F 3$ genes. ${ }^{83}$

\section{The Americas}

PEDV had been absent in the Americas until it emerged suddenly in the United States in April 2013. Since then, PEDV spread rapidly in swine herds through the country, resulting in huge economic losses. ${ }^{12}$ Sequence and phylogenetic analyses of the emergent US strains based on the full-genome indicated that they were most closely related to the Chinese strain AH2012 isolated in 2012, suggesting their potential origin from the People's Republic of China. ${ }^{58}$ Furthermore, recombination analysis revealed that two genotype IIa strains, AH2012 and CH/ZMDZY/11, were potential progenitors. ${ }^{58,65}$ Furthermore, the high-virulence US strains were identified to be responsible for subsequent serious PED outbreaks in South Korea, Taiwan, and Japan during 2013-2014. ${ }^{55,60,81,84}$

The second novel strain OH851 belonging to genotype Ib was detected in Ohio in January 2014, has multiple deletions and insertions in the $S$ gene, and is clustered closely with a Chinese $\mathrm{Ib}$ isolate HBQX/2010 based on the $S$ gene. Compared to the major US strains, the PEDV strain OH851 possesses low nucleotide identity in their $5^{\prime}$-end $S 1$ region (first 1,170 nt) and high nucleotide identity in the remaining $S$ gene. ${ }^{57,85}$ Possible recombination events might contribute to a rapid evolution of US strains. ${ }^{57}$ Recently, OH851-like strains have been detected in South Korea $^{56}$ and Japan ${ }^{81}$ in Asia, and Germany, ${ }^{15,16}$ Italy, ${ }^{17}$ the Netherlands, ${ }^{18}$ Belgium, ${ }^{19}$ France, ${ }^{20}$ Portugal,,${ }^{22}$ Slovenia, ${ }^{21}$ and Austria ${ }^{21}$ in Europe.

A novel variant TC-PC22A (GenBank accession number KM392224), which has a large deletion (197-aa) in the $\mathrm{N}$-terminal portion of the $\mathrm{S}$ protein, was recently isolated in the United States..$^{53}$

PED outbreaks have been recently reported in other countries in North, Central, and South America, including Mexico (July 2013), Peru (October 2013), the Dominican Republic (November 2013), Canada (April 2014), Columbia (March 2014), and Ecuador (July 2014). ${ }^{86}$

\section{Europe}

In May 2014, an outbreak of PED that occurred on a pig fattening farm was reported in Germany, and the PEDV isolates associated were genetically almost identical to the OH851 variant based on whole-genome sequencing. ${ }^{15}$ Thereafter, 
the OH851-like strains were detected from PED outbreaks in other European countries during 2014-2015, including in France, ${ }^{20}$ Italy, ${ }^{17}$ Austria, ${ }^{21}$ Belgium, ${ }^{19}$ the Netherlands, ${ }^{18}$ Portugal, ${ }^{22}$ and Slovenia. ${ }^{21}$

Different from the aforementioned European countries, in 2014, severe PED outbreaks occurred in Ukraine, and the isolates clustered phylogenetically with genotype IIa US strains. ${ }^{23}$ Close attention should be paid to investigate and prevent the possible spread of virulent IIa US-like PEDV into other regions of Europe.

\section{Oceania}

In November 2014, a PED outbreak characterized by significant diarrhea and high mortality in piglets occurred in a swine farm in Oahu Island, Hawaii, Oceania. The Hawaiian isolates clustered phylogenetically with the OH851-like strains. ${ }^{25}$

\section{Virus transmission}

The fecal-oral route is believed to be the main means of PEDV transmission. ${ }^{26}$ Fomites contaminated by PEDVcontaining feces could be associated with the introduction and rapid spread of the virus. The fomites include transport vehicles, equipment, feedbags, personnel (eg, clothes, boots), feed, animals (eg, pigs, birds, cats), and other fomites. ${ }^{87-89}$ Clinically asymptomatic PEDV-infected finishing pigs could be the reservoir of the virus. ${ }^{89}$ The introduction of pigs from countries or regions with PED outbreaks is of high risk; a PED outbreak that recently occurred in Austria was attributed to purchase of piglets from Germany. ${ }^{21}$

Contaminated feed has also been identified as a vehicle to transmit PEDV, as has been observed in the results of recent epidemiological investigations performed in the USA and Japan. ${ }^{88,89}$ Spray-dried porcine plasma as the feed additive was suspected to be a potential source of the virus in a report by Pasick et al..$^{90}$ However, scientific support of this route remains debated since two studies on whether spray-dried porcine plasma tested positive for PEDV RNA was not infectious to the seronegative piglets gave conflicting results. ${ }^{90,91}$

Some studies have raised the possible role of airborne transmission. Airborne viable PEDV virus has been detected in air samples from an isolation room with infected pigs and PEDV RNA was detected by real-time polymerase chain reaction (RT-PCR) in air up to 10 miles downwind from an infected site. ${ }^{92}$ The findings that the direction of disease spread correlated qualitatively with wind direction reported by Beam et $\mathrm{al}^{93}$ provide support to the hypothesis of airborne PEDV spread. However, this study did not provide a definitive assessment of airborne spread of the virus; more studies should be conducted to assess the possibility of airborne transmission.

\section{Clinical signs, lesions, and PEDV replication dynamics in intestines Clinical signs}

PEDV can infect pigs of any age; however, the severity of this disease is variable and is highly dependent on the age of the infected animals. ${ }^{94}$ PEDV infection usually results in high morbidity (up to $100 \%$ ) and mortality (up to $80 \%-100 \%$ ) in suckling piglets, especially those less than 1 week old. ${ }^{12,95}$ The clinical signs in suckling piglets were characterized by severe watery diarrhea as well as vomiting (not in all infected piglets), followed by severe dehydration and emaciation leading to death. ${ }^{10-12,60}$ In the weaner, fattener, and adult pigs, clinical signs usually recover around 1 week after the onset of the disease, ${ }^{96}$ and the mortality rates generally did not exceed $4 \% .{ }^{12,95}$ The higher susceptibility and more severe disease in nursing piglets compared to older pigs could be partially attributed to the slower regeneration of enterocytes (5-7 days) in neonatal piglets compared to those older than 3 weeks (2-3 days). ${ }^{97}$

In addition, the virulence of different PEDV strains or genotypes was shown to be different, as observed in the results of recent studies. The new PEDV variants belonging to genotype II, which included genotype IIb strains emerged in the People's Republic of China from late 2010 (eg, LC, AJ1102) and Vietnam in 2013, ${ }^{64,68,98}$ and the genotype IIa PEDV strains currently prevalent in the People's Republic of China and US-like strains in the United States, Taiwan, South Korea, Japan, and Ukraine were shown to be highly virulent. ${ }^{23,41,55,58-62,74,81,84,99,100}$ Those OH851-like variants, which belong to genotype $\mathrm{Ib}$ and are distributed in the People's Republic of China, the United States, South Korea, Japan, and Europe, have generally been associated with mildto-moderate clinical outbreaks. ${ }^{15,20,21,56,57,81}$ However, severe cases associated with $\mathrm{OH} 851$-like strains were reported in Germany, where mortality in suckling piglets reached almost $70 \%$ in one of two sow farms, and in Portugal (mortality rate was not given). ${ }^{16,22} \mathrm{~A}$ comparison experiment on the pathogenesis of three US prototype strains and one OH851-like variant reported recently by Chen et al ${ }^{100}$ demonstrated that the OH851-like variant had significantly diminished clinical signs, virus shedding in feces, gross or histopathological lesions in small intestines, and immunohistochemistry (IHC) scores in ileum compared to three US prototype isolates. 
In the future, more experiments and investigations on the pathogenicity of OH851-like PEDV variants in pigs should be carried out.

\section{Gross and histological lesions}

Gross lesions are confined to the gastrointestinal tract and characterized by a distended stomach filled with curdled milk and thin, transparent intestine walls with accumulation of watery yellow fluid in the intestinal lumen. ${ }^{12,101}$

Histological lesions of PEDV infection include cytoplasmic vacuolation and exfoliation of small-intestinal enterocytes in superficial villous, necrosis of scattered enterocytes followed by sloughing, and contraction of the subjacent villous lamina propria containing apoptotic cells. The extent of intestinal villi shortening was associated with the stage of the infection or disease process. ${ }^{101}$ Massive loss of absorptive enterocytes by PEDV infection results in a consequence of malabsorption, followed by watery diarrhea and dehydration in piglets.

\section{PEDV replication dynamics in intestines}

Porcine small-intestinal villous enterocytes express large amounts of aminopeptidase $\mathrm{N}$ identified as the cellular receptor for PEDV. High density of the receptor on enterocytes allows PEDV to enter and replicate through virus-receptor interactions. ${ }^{102}$ Replication of PEDV was classically confined to the intestines; however, a recent research showed the PEDV replication in alveolar macrophages in vitro and in vivo. ${ }^{103}$

Saif et al $^{96}$ described that PEDV replicates in the cytoplasm of mature enterocytes within 12-18 hours postinfection (hpi) and typically reaches maximum replication around 24-36 hours. ${ }^{96}$ A recent study reported by Wang et al ${ }^{1}$ showed that rapid PEDV replication was detected using IHC as early as 12 hpi from an artificially infected 3-day-old pig without clinical signs; at this time point, apparent immunostaining was visible in the upper small intestine (duodenum, proximal jejunum, and mid-jejunum). PEDV replication hereafter spread into entire jejunum and ileum. The maximum virus replication was detected in the jejunum and ileum in infected piglets within 24 hours after the onset of clinical signs (acute phase of disease) and coincided with the appearance of severe watery diarrhea and dehydration. Another experiment conducted in 5-day-old pigs by Chen et al ${ }^{100}$ showed that PEDV IHC staining was observed in 100\% ileums, 60\%-100\% ceca, and $40 \%-100 \%$ colons (IHC was not performed in duodenum and jejunum) at 3 days postinfection (dpi); however, PEDV antigen was only detected in $40 \%$ ileum at 7 dpi.

\section{Diagnosis}

Since PEDV-associated diarrhea is clinically indistinguishable from diarrhea caused by other viral pathogens, including transmissible gastroenteritis virus, porcine deltacoronavirus, and porcine rotavirus, differential diagnosis to identify the PEDV must be conducted in the laboratory. ${ }^{24}$

PEDV nucleic acid detection from fecal or intestinal samples by conventional or RT-PCR is the most frequent assay used at present because of its simplicity and speed. ${ }^{86}$ The primer designs of RT-PCR assays are generally based on the amplification of fragments within the $M, N$, or $S$ genes associated with high sensitivity and specificity.

Immunochromatographic assay kits and some enzyme linked immunosorbent assays (ELISAs), which are usually based on the use of monoclonal antibodies against PEDV, can be used at farms or in the laboratory. Immunochromatographic assay kits generally have lower sensitivity than the PCR assays; however, they allow for prompt diagnosis within 10 minutes. Thus, they are particularly effective for quickly determining quarantine or slaughter policies in the field conditions where the amount of virus in the tested fecal samples collected from diseased animals at the acute stage diarrhea is generally very high. ${ }^{96}$

IHC is most suitable for the detection of PEDV antigen in the infected cells in formalin-fixed sections of small intestine, and is a technique by which the level and dynamics of PEDV replication in the intestines can be evaluated. ${ }^{1,100}$

Serological assays including ELISA, indirect fluorescent antibody staining, and virus neutralization tests have been regularly used for the detection of PEDV antibodies, which can provide epidemiological information of the virus or immunity level assessment after vaccine immunization. Recently, two indirect ELISA assays used to detect the anti-PEDV IgG/ IgA in serum and colostrum samples and the anti-PEDV IgA in fecal and serum samples have been developed. ${ }^{104,105}$

\section{Immune responses to PEDV infection}

Viral infections induce both innate and adaptive immune responses. The innate immune system is the first line of host defense in response to viral infection. It initiates the production of Type I IFNs (IFN- $\alpha / \beta)$ and proinflammatory cytokines through the recognition of the pathogen-associated molecular patterns by host pattern recognition receptors and establishes antiviral states, which are highly effective in resisting and controlling infections. ${ }^{106}$ Type I IFN plays an important role in antiviral immune response; however, several recent reports showed that PEDV has the ability to suppress the IFN antiviral response for 
its survival advantage. ${ }^{45,106-109}$ These in vitro studies have identified eleven viral proteins responsible for this suppression, which include nsp1, nsp3, nsp5, nsp7, nsp14, nsp15, nsp16, ORF3, E, $\mathrm{M}$, and N. The molecular mechanisms of PEDV-inhibition Type I IFN production include: 1) papain-like proteinase 2 of PEDV antagonizing the IFN response by deubiquitinating retinoic acidinducible gene-I and stimulator of IFN genes; ${ }^{107}$ 2) PEDV N protein suppressing the IFN regulatory factor 3 (IRF3) and nuclear factor kappa-B activities and antagonizing the IFN- $\beta$ production by disrupting the interaction between IRF3 and TANK-binding kinase 1.453 ) PEDV infection in intestinal epithelial cells inhibiting dsRNA-mediated IFN- $\beta$ induction by interfering with IRF3 activity associated with retinoic acid-inducible gene-I-mediated signaling pathway; ${ }^{108}$ 4) PEDV nsp1 interrupting the enhanceosome assembly of IRF3 and cAMP response element binding protein by degrading CREB-binding protein via the proteasomedependent pathway; ${ }^{106}$ and 5) PEDV-encoded 3C-like protease (nsp5)-mediated proteolytic cleavage of NEMO directly being involved in inhibition of IFN- $\beta$ transcription. ${ }^{109}$

A report by Annamalai et $\mathrm{al}^{110}$ showed that the innate immune responses to PEDV infection vary with the age of host. PEDV-infected suckling pigs had significantly lower natural killer (NK) cell frequencies, undetectable NK cell activity, and lower IFN- $\gamma$-producing NK cells in blood and ileum compared to PEDV-infected weaned pigs. Proinflammatory cytokine profiles of PEDV-infected suckling pigs differed from those of PEDV-infected weaned pigs. The infected suckling pigs have higher and earlier increases in serum IFN- $\alpha$, but lower serum interleukin (IL)- 8 and tumor necrosis factor (TNF)- $\alpha$ levels compared to infected weaned pigs. $\mathrm{CD}^{+} \mathrm{CD}^{+} \mathrm{T}$-cell frequencies were significantly higher in ileum of suckling pigs than in weaned pigs, whereas there was no difference in $\mathrm{CD}^{+} \mathrm{CD}^{+}$ T-cell frequencies. Deficiency in innate immune function of NK cells may have contributed to the higher severity of PEDV infection in suckling versus weaned piglets.

Dendritic cells (DCs), the most potent antigen-presenting cells, are widely distributed beneath the intestinal epithelium and act as a particularly early target for virus contact. ${ }^{111}$ Mature DCs present captured antigens and initiate T-cell adaptive immune responses and stimulate memory responses. The intestinal DC network consisted of DCs derived from monocytes and pre-DCs. Gao et $\mathrm{al}^{111}$ investigated the effects of attenuated CV777 on the function of porcine monocyte-derived dendritic cells (Mo-DCs) and intestinal DCs. ${ }^{111}$ Attenuated CV777 stimulates Mo-DCs maturation and enhances the ability of mature Mo-DCs to sample and present antigen. Attenuated CV777 infection of immature and mature Mo-DCs resulted in a significant increase in IL-12 and IFN- $\gamma$ expression, but no change in expression profile of IL-10. Attenuated CV777 also enhances the ability of porcine intestinal DCs to present, migrate, and induce the activation of T lymphocytes in vivo and in vitro. Both Mo-DCs and intestinal DCs played a role in priming an effective and positive response when infected with attenuated CV777.

There is a lack of information on the T-cell-mediated immune responses to PEDV infection. Lymphocyte proliferative responses in mucosal and systemic lymphoid tissues were studied in conventional piglets inoculated with the virulent and attenuated CV777. ${ }^{12}$ Specific lymphocyte proliferative responses were detected in the pigs inoculated with the virulent PEDV at postinoculation days 4-21, especially in the mesenteric lymph nodes and the blood, and this response in the spleen was lower and less regular. Specific lymphoproliferative responses were detected later (14 days post-infection [PID]) and were lower in the pigs inoculated with the attenuated virus.

The importance of humoral immune response in gastroenteric viral infections of swine is well recognized. Virusspecific antibody response with primarily the secretory immunoglobulin A was inducted actively by the infection of wild or attenuated virus in pigs/sows, and passive lactogenic immunity is the control strategy against PEDV infection. de Arriba et $\mathrm{al}^{113}$ studied the isotype-specific antibody-secreting cells (ASC) in systemic and mucosal-associated lymphoid tissues and serum antibody responses in conventional pigs inoculated orally with the virulent and attenuated CV777. The pigs exposed to the virulent CV777 showed a large number of $\mathrm{IgG}$ and IgA ASC on PID 21 mainly in the gut-associated lymphoid tissues. In contrast, IgA ASC could be detected only in small numbers in the mesenteric lymph nodes of the pigs exposed to attenuated CV777, and significantly lower IgG antibody and no IgA antibody were detected in the serum. Ouyang et $\mathrm{al}^{114}$ evaluated humoral immune status in PEDV-infected sows under field conditions. In the PEDV-infected sows, PEDV-specific IgA antibody and virus neutralization titers in blood remained high up to 6 months postinfection. In this study, higher levels of IgA and IgG ASC were observed in spleen than in intestines, which is inconsistent with de Arriba et al's ${ }^{113}$ finding in piglets.

\section{Vaccines Commercial vaccines}

Before 2013, PEDV was present only in Europe and Asia. In Europe, PED has less economic impact; thus, no vaccines have been developed and used. In contrast, PEDV has been circulating in Asia for several decades, and results in enormous economic loss especially in the People's Republic of China, South Korea, and Japan. Vaccination has been used for many years 
in these Asian countries, and vaccines used include inactivated and live-attenuated vaccines (Table 1). In the People's Republic of China, three CV777-based inactivated and live-attenuated bivalent or trivalent vaccines were licensed in 1999, 2003, and 2014, respectively. A genotype IIa strain ZJ08-based attenuated bivalent vaccine was licensed by the Chinese Ministry of Agriculture in 2015. A genotype IIb strain AJ1102-based inactivated vaccine developed by Wuhan Keqian was approved for clinical trial in 2014. In Japan, an attenuated vaccine using cell cultureadapted strain 83P-5, namely, P-5V, has been administered on a voluntary basis to sows since $1997,{ }^{26}$ and now the 100 -passaged 83P-5 strain was licensed for use as attenuated monovalent and bivalent vaccines by Nisseiken Co., Ltd., Tokyo, Japan. ${ }^{40}$ Cell-culture-attenuated DR13 (100 passages) was licensed and used as an oral vaccine in South Korea since 2004, and it was registered and commercialized in the Philippines in 2011. ${ }^{26}$ A series of strain SM98P-based killed, live, and combination vaccines are offered by Komipharm International Co., Ltd. Kyonggi-Do, South Korea. Since April 2013, the emerged PEDV outbreaks led to huge economic losses to swine industry in USA. To meet the emergency need, an RNA particle vaccine (Harrisvaccines) based on an alphavirus vector for the PEDV $S$ gene, as well as a killed vaccine (Zoetis, Florham Park, NJ, USA), has been granted conditional United States Department of Agriculture licenses in 2014.

\section{Issues on current development of PEDV vaccines}

Vaccination is a fundamental tool in the control and prevention of PED during epidemic or endemic outbreaks. Although the classical GIa strains-based vaccines played important roles in the control of PEDV infections, their effectiveness in the field, especially in the outbreaks by new variants after 2010, are still being debated. ${ }^{10,69,74,115}$ Nowadays, many veterinary researchers have focused on the development of more effective PEDV vaccines. Here, we discuss briefly two issues on the current development of PEDV vaccines: the selection of vaccine strains and vaccination routes.

An ideal candidate strain used for PEDV vaccine is expected to have the ability to confer excellent protection against different field strains of PEDV. So far, there are limited experimental studies on the cross protection between the PEDV strains of different genotypes. Goede et $\mathrm{al}^{116}$ demonstrated that the morbidity and mortality (up to 1 week of age) in 3-day-old piglets born to sows exposed 7 months earlier to a mild strain (OH851, genotype $\mathrm{Ib}$ ) after the challenge with a virulent genotype IIa US strain were $43 \%$ and $0 \%$, compared to $100 \%$ and $67 \%$ of that in piglets born to sows not previously exposed, respectively. The result of cross-serum neutralization test in Vero cells from a recent report by Wang et $\mathrm{al}^{117}$ showed that more anti-S polyclonal antibodies were needed to cross neutralize different genotype strains.

Control of PEDV generally requires maternal vaccination strategies to stimulate lactogenic immunity for passive protection of suckling pigs. ${ }^{26}$ Protection against the enteric disease is primarily dependent on the presence of secretory IgA antibodies in the intestinal mucosa, and oral vaccination can stimulate mucosal immunity and produce protective mucosal and serum IgA antibodies more effectively than other vaccination routes such as intramuscular

Table I Summary of commercial and conditionally licensed porcine epidemic diarrhea vaccines

\begin{tabular}{|c|c|c|c|c|c|}
\hline Year & Type & Company/institution, country & Vaccine strain & Genotype & Route \\
\hline \multicolumn{6}{|l|}{ Licensed } \\
\hline 1999 & Killed, bivalent (P-T) & HVRI, People's Republic of China & CV777 & la & Houhai acupoint \\
\hline 2003 & Live, bivalent (P-T) & HVRI, People's Republic of China & CV777, attenuated & la & Houhai acupoint \\
\hline 2004, 20II & Live & South Korea, the Philippines & DRI3, attenuated & la & Oral \\
\hline 1 & Killed, SuiShot ${ }^{\circledR}$ PT-I00 & CAVAC, South Korea & 1 & 1 & IM \\
\hline I & Killed, PRO-VAC ${ }^{\circledR}$ PED-Fc & Komipharm, South Korea & I & I & IM \\
\hline I & Live, PRO-VAC ${ }^{\circledR}$ PED & Komipharm, South Korea & SM98P & la & IM \\
\hline I & Live, PRO-VAC ${ }^{\circledR}$ TRP & Komipharm, South Korea & SM98P & la & IM \\
\hline I & Killed, PRO-VAC ${ }^{\circledR}$ TP & Komipharm, South Korea & SM98P & la & IM \\
\hline I & Live & Nisseiken, Japan & $P-5 V$ & la & IM \\
\hline 1 & Live, bivalent (P-T) & Nisseiken, Japan & P-5V & la & IM \\
\hline 2014 & Live, trivalent (P-T-R) & HVRI, People's Republic of China & CV777, attenuated & la & Houhai acupoint \\
\hline 2015 & Live, bivalent (P-T) & DBN, People's Republic of China & ZJ08, attenuated & Ila & IM \\
\hline \multicolumn{6}{|c|}{ Conditionally licensed } \\
\hline 2014 & RNA & Harrisvaccines, Merck, USA & I & l & IM \\
\hline 2014 & Killed & Zoetis, USA & 1 & I & IM \\
\hline
\end{tabular}

Abbreviations: PEDV, porcine epidemic diarrhea virus; P-T, PEDV plus TGEV; P-T-R, PEDV plus TGEV plus Rotavirus; TGEV, transmissible gastroenteritis virus; HVRI, Harbin Veterinary Research Institute, Chinese Academy of Agricultural Sciences; CAVAC, ChoongAng Vaccine Laboratories Co., Ltd; DBN, Beijing Dabeinong Technology Group Co., Ltd.; IM: intramuscular; /, not available. 
(IM) ${ }^{26}$ Song et al ${ }^{118}$ reported that oral administration with live-attenuated PEDV DR13 vaccine in pregnant sows reduced the mortality of suckling piglets more effectively compared to those administered by IM route (13\% versus $60 \%$ ), and exhibited higher IgA antibody levels. However, some challenges exist in the development of an oral PEDV vaccine, which include balancing sufficient virus attenuation and vaccine immunogenicity, improving the inconvenience of inoculation in swine herds, and developing effective adjuvants.

\section{Conclusion}

Currently, PED is globally recognized as an emerging and reemerging disease that has resulted in great economic losses to the swine industry worldwide. PEDV research has become a hot topic in veterinary medicine since late 2010 . Increasing research has provided a more in-depth understanding of PEDV. Nevertheless, further studies are needed to be conducted on the molecular epidemiology and evolutionary dynamics, pathogenic difference among the PEDV variants, genetic mechanism of PEDV attenuation in cell culture, cross protection between the PEDV strains of different genotypes, and transmission mechanisms of PEDV. The better understanding of PEDV will contribute to the development of effective vaccines and the establishment of biosecurity measures to prevent and control the disease.

\section{Acknowledgments}

This work was supported by grants from Major Science and Technology Program in Henan Province (grant number 131100110200), Innovation Scientists and Technicians Troop Construction Projects of Henan Province (grant number 142101510001), Talents Plan for Scientific and Technological Innovation in Henan Province (grant number 144200510002), and Science and Technology Innovation Team in Henan Province (team number C20130005).

\section{Disclosure}

The authors report no conflicts of interest in this work.

\section{References}

1. Wang Y, Gao X, Yao Y, et al. The dynamics of Chinese variant porcine epidemic diarrhea virus production in Vero cells and intestines of 2-day old piglets. Virus Res. 2015;208:82-88.

2. Wood EN. An apparently new syndrome of porcine epidemic diarrhoea. Vet Rec. 1977;100(12):243-244.

3. Pensaert MB, de Bouck P. A new coronavirus-like particle associated with diarrhea in swine. Arch Virol. 1978;58(3):243-247.

4. Pijpers A, van Nieuwstadt AP, Terpstra C, Verheijden JH. Porcine epidemic diarrhoea virus as a cause of persistent diarrhoea in a herd of breeding and finishing pigs. Vet Rec. 1993;132(6):129-131.
5. Nagy B, Nagy G, Meder M, Mocsari E. Enterotoxigenic Escherichia coli, rotavirus, porcine epidemic diarrhoea virus, adenovirus and calicilike virus in porcine postweaning diarrhoea in Hungary. Acta Vet Hung. 1996;44(1):9-19.

6. Pritchard GC, Paton DJ, Wibberley G, Ibata G. Transmissible gastroenteritis and porcine epidemic diarrhoea in Britain. Vet Rec. 1999;144(22):616-618.

7. Takahashi K, Okada K, Ohshima K. An outbreak of swine diarrhea of a new-type associated with coronavirus-like particles in Japan. Nihon Juigaku Zasshi. 1983;45(6):829-832.

8. Xuan H, Xing D, Wang D, Zhu W, Zhao F, Gong H. Study on the culture of porcine epidemic diarrhea virus adapted to fetal porcine intestine primary cell monolayer. Chin J Vet Sci. 1984;4(3):202-208.

9. Kweon CH, Kwon BJ, Jung TS, et al. Isolation of porcine epidemic diarrhea virus (PEDV) in Korea. Korean J Vet Res. 1993;33(2):249-254.

10. Sun RQ, Cai RJ, Chen YQ, Liang PS, Chen DK, Song CX. Outbreak of porcine epidemic diarrhea in suckling piglets, China. Emerg Infect Dis. 2012;18(1):161-163.

11. Wang J, Zhao P, Guo L, et al. Porcine epidemic diarrhea virus variants with high pathogenicity, China. Emerg Infect Dis. 2013;19(12):2048-2049.

12. Stevenson GW, Hoang H, Schwartz KJ, et al. Emergence of Porcine epidemic diarrhea virus in the United States: clinical signs, lesions, and viral genomic sequences. J Vet Diagn Invest. 2013;25(5):649-654.

13. EFSA Panel on Animal Health and Welfare. Scientific opinion on porcine epidemic diarrhoea and emerging pig deltacoronavirus. EFSA J. 2014;12(10):3877.

14. Cima G. PED virus reinfecting U.S. herds. Virus estimated to have killed 7 million-plus pigs. J Am Vet Med Assoc. 2014;245(2):166-167.

15. Hanke D, Jenckel M, Petrov A, et al. Comparison of porcine epidemic diarrhea viruses from Germany and the United States, 2014. Emerg Infect Dis. 2015;21(3):493-496.

16. Stadler J, Zoels S, Fux R, et al. Emergence of porcine epidemic diarrhea virus in southern Germany. BMC Vet Res. 2015;11:142.

17. Boniotti MB, Papetti A, Lavazza A, et al. Porcine epidemic diarrhea virus and discovery of a recombinant swine enteric coronavirus, Italy. Emerg Infect Dis. 2016;22(1):83-87.

18. Van der Wolf PJ, Van Walderen A, Meertens MN, et al. First case of porcine epidemic diarrhoea (PED) caused by a new variant of PED virus in the Netherlands. Paper presented at: Proceeding 7th European Symposium of Porcine Health Management, April 22-24, 2015, Nantes, France.

19. Theuns S, Conceicao-Neto N, Christiaens I, et al. Complete genome sequence of a porcine epidemic diarrhea virus from a novel outbreak in Belgium, January 2015. Genome Announc. 2015;3(3): e00506-15.

20. Grasland B, Bigault L, Bernard C, et al. Complete genome sequence of a porcine epidemic diarrhea s gene indel strain isolated in France in December 2014. Genome Announc. 2015;3(3):e00535-15.

21. Steinrigl A, Revilla Fernandez S, Stoiber F, Pikalo J, Sattler T, Schmoll F. First detection, clinical presentation and phylogenetic characterization of Porcine epidemic diarrhea virus in Austria. BMC Vet Res. 2015;11(1):310.

22. Mesquita JR, Hakze-van der Honing R, Almeida A, Lourenco M, van der Poel WH, Nascimento MS. Outbreak of porcine epidemic diarrhea virus in Portugal, 2015. Transbound Emerg Dis. 2015;62(6):586-588.

23. Dastjerdi A, Carr J, Ellis RJ, Steinbach F, Williamson S. Porcine epidemic diarrhea virus among farmed pigs, Ukraine. Emerg Infect Dis. 2015;21(12):2235-2237.

24. Opriessnig T. Re-emergence of porcine epidemic diarrhea virus in the global pig population. Vet J. 2015;204(2):131.

25. Jarvis MC, Lam HC, Zhang Y, et al. Genomic and evolutionary inferences between American and global strains of porcine epidemic diarrhea virus. Prev Vet Med. 2016;123:175-184.

26. Song D, Park B. Porcine epidemic diarrhoea virus: a comprehensive review of molecular epidemiology, diagnosis, and vaccines. Virus Genes. 2012;44(2):167-175. 
27. Brian DA, Baric RS. Coronavirus genome structure and replication. Curr Top Microbiol Immunol. 2005;287:1-30.

28. Bosch BJ, van der Zee R, de Haan CA, Rottier PJ. The coronavirus spike protein is a class I virus fusion protein: structural and functional characterization of the fusion core complex. $J$ Virol. 2003;77(16):8801-8811.

29. Chang SH, Bae JL, Kang TJ, et al. Identification of the epitope region capable of inducing neutralizing antibodies against the porcine epidemic diarrhea virus. Mol Cells. 2002;14(2):295-299.

30. Kang TJ, Seo JE, Kim DH, Kim TG, Jang YS, Yang MS. Cloning and sequence analysis of the Korean strain of spike gene of porcine epidemic diarrhea virus and expression of its neutralizing epitope in plants. Protein Exp Purif. 2005;41(2):378-383.

31. Cruz DJ, Kim CJ, Shin HJ. Phage-displayed peptides having antigenic similarities with porcine epidemic diarrhea virus (PEDV) neutralizing epitopes. Virology. 2006;354(1):28-34.

32. Sun D, Feng L, Shi H, et al. Identification of two novel B cell epitopes on porcine epidemic diarrhea virus spike protein. Vet Microbiol. 2008;131(1-2):73-81.

33. Park JE, Cruz DJ, Shin HJ. Receptor-bound porcine epidemic diarrhea virus spike protein cleaved by trypsin induces membrane fusion. Arch Virol. 2011;156(10):1749-1756.

34. Huy NX, Kim SH, Yang MS, Kim TG. Immunogenicity of a neutralizing epitope from porcine epidemic diarrhea virus: M cell targeting ligand fusion protein expressed in transgenic rice calli. Plant Cell Rep. 2012;31(10):1933-1942.

35. Meng F, Suo S, Zarlenga DS, et al. A phage-displayed peptide recognizing porcine aminopeptidase $\mathrm{N}$ is a potent small molecule inhibitor of PEDV entry. Virology. 2014;456-457:20-27.

36. Oh J, Lee KW, Choi HW, Lee C. Immunogenicity and protective efficacy of recombinant $\mathrm{S} 1$ domain of the porcine epidemic diarrhea virus spike protein. Arch Virol. 2014;159(11):2977-2987.

37. Park JE, Cruz DJ, Shin HJ. Clathrin- and serine proteases-dependent uptake of porcine epidemic diarrhea virus into Vero cells. Virus Res. 2014;191:21-29.

38. Wicht $\mathrm{O}, \mathrm{Li} \mathrm{W}$, Willems $\mathrm{L}$, et al. Proteolytic activation of the porcine epidemic diarrhea coronavirus spike fusion protein by trypsin in cell culture. J Virol. 2014;88(14):7952-7961.

39. Ge JW, Liu DQ, LiYJ. Construction of recombinant lactobacilli expressing the core neutralizing epitope (COE) of porcine epidemic diarrhea virus and a fusion protein consisting of $\mathrm{COE}$ and Escherichia coli heat-labile enterotoxin $\mathrm{B}$, and comparison of the immune responses by orogastric immunization. Can J Microbiol. 2012;58(11):1258-1267.

40. Sato T, Takeyama N, Katsumata A, Tuchiya K, Kodama T, Kusanagi K. Mutations in the spike gene of porcine epidemic diarrhea virus associated with growth adaptation in vitro and attenuation of virulence in vivo. Virus Genes. 2011;43(1):72-78.

41. Chen Q, Li G, Stasko J, et al. Isolation and characterization of porcine epidemic diarrhea viruses associated with the 2013 disease outbreak among swine in the United States. J Clin Microbiol. 2014;52(1):234-243.

42. Klumperman J, Locker JK, Meijer A, Horzinek MC, Geuze HJ, Rottier PJ. Coronavirus $\mathrm{M}$ proteins accumulate in the Golgi complex beyond the site of virion budding. J Virol. 1994;68(10):6523-6534.

43. Vennema H, Godeke GJ, Rossen JW, et al. Nucleocapsid-independent assembly of coronavirus-like particles by co-expression of viral envelope protein genes. EMBO J. 1996;15(8):2020-2028.

44. Spaan W, Delius H, Skinner M, et al. Coronavirus mRNA synthesis involves fusion of non-contiguous sequences. EMBO J. 1983;2(10):1839-1844.

45. Ding Z, Fang L, Jing H, et al. Porcine epidemic diarrhea virus nucleocapsid protein antagonizes beta interferon production by sequestering the interaction between IRF3 and TBK1. $J$ Virol. 2014;88(16):8936-8945.

46. Wang $\mathrm{K}, \mathrm{Lu} \mathrm{W}$, Chen J, et al. PEDV ORF3 encodes an ion channel protein and regulates virus production. FEBS Lett. 2012;586(4): 384-391.
47. Song DS, Yang JS, Oh JS, Han JH, Park BK. Differentiation of a Vero cell adapted porcine epidemic diarrhea virus from Korean field strains by restriction fragment length polymorphism analysis of ORF 3 . Vaccine. 2003;21(17-18):1833-1842.

48. Lawrence PK, Bumgardner E, Bey RF, Stine D, Bumgarner RE. Genome sequences of porcine epidemic diarrhea virus: in vivo and in vitro phenotypes. Genome Announc. 2014;2(3):e00503-14.

49. Shirato K, Matsuyama S, Ujike M, Taguchi F. Role of proteases in the release of porcine epidemic diarrhea virus from infected cells. $J$ Virol. 2011;85(15):7872-7880.

50. Hofmann M, Wyler R. Propagation of the virus of porcine epidemic diarrhea in cell culture. J Clin Microbiol. 1988;26(11): 2235-2239.

51. Kusanagi K, Kuwahara H, Katoh T, et al. Isolation and serial propagation of porcine epidemic diarrhea virus in cell cultures and partial characterization of the isolate. J Vet Med Sci. 1992;54(2):313-318.

52. Kweon CH, Kwon BJ, Lee JG, Kwon GO, Kang YB. Derivation of attenuated porcine epidemic diarrhea virus (PEDV) as vaccine candidate. Vaccine. 1999;17(20-21):2546-2553.

53. Oka T, Saif LJ, Marthaler D, et al. Cell culture isolation and sequence analysis of genetically diverse US porcine epidemic diarrhea virus strains including a novel strain with a large deletion in the spike gene. Vet Microbiol. 2014;173(3-4):258-269.

54. Chen F, Zhu Y, Wu M, et al. Comparative genomic analysis of classical and variant virulent parental/attenuated strains of porcine epidemic diarrhea virus. Viruses. 2015;7(10):5525-5538.

55. Lee S, Lee C. Outbreak-related porcine epidemic diarrhea virus strains similar to US strains, South Korea, 2013. Emerg Infect Dis. 2014;20(7):1223-1226.

56. Lee S, Park GS, Shin JH, Lee C. Full-genome sequence analysis of a variant strain of porcine epidemic diarrhea virus in South Korea. Genome Announc. 2014;2(6):e01116-14.

57. Wang L, Byrum B, Zhang Y. New variant of porcine epidemic diarrhea virus, United States, 2014. Emerg Infect Dis. 2014;20(5):917-919.

58. Huang YW, Dickerman AW, Pineyro P, et al. Origin, evolution, and genotyping of emergent porcine epidemic diarrhea virus strains in the United States. MBio. 2013;4(5):e00737-e00713.

59. Song D, Huang D, Peng Q, et al. Molecular characterization and phylogenetic analysis of porcine epidemic diarrhea viruses associated with outbreaks of severe diarrhea in piglets in Jiangxi, China 2013. PLoS One. 2015;10(3): $\mathrm{e} 0120310$.

60. Lin CN, Chung WB, Chang SW, et al. US-like strain of porcine epidemic diarrhea virus outbreaks in Taiwan, 2013-2014. J Vet Med Sci. 2014;76(9):1297-1299.

61. Chiou HY, Huang YL, Deng MC, et al. Phylogenetic analysis of the spike (S) gene of the new variants of porcine epidemic diarrhoea virus in Taiwan. Transbound Emerg Dis. Epub April 22, 2015.

62. Sung MH, Deng MC, Chung YH, et al. Evolutionary characterization of the emerging porcine epidemic diarrhea virus worldwide and 2014 epidemic in Taiwan. Infect Genet Evol. 2015;36:108-115.

63. Chung HC, Nguyen VG, Moon HJ, et al. Isolation of porcine epidemic diarrhea virus during outbreaks in South Korea, 2013-2014. Emerg Infect Dis. 2015;21(12):2238-2240.

64. Vui DT, Thanh TL, Tung N, et al. Complete genome characterization of porcine epidemic diarrhea virus in Vietnam. Arch Virol. 2015;160(8):1931-1938.

65. Tian PF, Jin YL, Xing G, Qv LL, Huang YW, Zhou JY. Evidence of recombinant strains of porcine epidemic diarrhea virus, United States, 2013. Emerg Infect Dis. 2014;20(10):1735-1738.

66. Li R, Qiao S, Yang Y, et al. Genome sequencing and analysis of a novel recombinant porcine epidemic diarrhea virus strain from Henan, China. Virus Genes. 2016;52(1):91-98.

67. Li W, Li H, Liu Y, et al. New variants of porcine epidemic diarrhea virus, China, 2011. Emerg Infect Dis. 2012;18(8):1350-1353.

68. Chen F, Pan Y, Zhang X, et al. Complete genome sequence of a variant porcine epidemic diarrhea virus strain isolated in China. $J$ Virol. 2012;86(22):12448. 
69. Pan $\mathrm{Y}$, Tian $\mathrm{X}, \mathrm{Li} \mathrm{W}$, et al. Isolation and characterization of a variant porcine epidemic diarrhea virus in China. Virol J. 2012;9:195.

70. Gao Y, Kou Q, Ge X, Zhou L, Guo X, Yang H. Phylogenetic analysis of porcine epidemic diarrhea virus field strains prevailing recently in China. Arch Virol. 2013;158(3):711-715.

71. Yang X, Huo JY, Chen L, et al. Genetic variation analysis of reemerging porcine epidemic diarrhea virus prevailing in central China from 2010 to 2011. Virus Genes. 2013;46(2):337-344.

72. Chen J, Liu X, Shi D, et al. Detection and molecular diversity of spike gene of porcine epidemic diarrhea virus in China. Viruses. 2013;5(10):2601-2613.

73. Wang XM, Niu BB, Yan H, et al. Genetic properties of endemic Chinese porcine epidemic diarrhea virus strains isolated since 2010. Arch Virol. 2013;158(12):2487-2494.

74. Tian Y, Yu Z, Cheng K, et al. Molecular characterization and phylogenetic analysis of new variants of the porcine epidemic diarrhea virus in Gansu, China in 2012. Viruses. 2013;5(8):1991-2004.

75. Sun R, Leng Z, Zhai SL, Chen D, Song C. Genetic variability and phylogeny of current Chinese porcine epidemic diarrhea virus strains based on spike, ORF3, and membrane genes. ScientificWorldJournal. 2014;2014:208439.

76. Hao J, Xue C, He L, Wang Y, Cao Y. Bioinformatics insight into the spike glycoprotein gene of field porcine epidemic diarrhea strains during 2011-2013 in Guangdong, China. Virus Genes. 2014;49(1):58-67.

77. Yang DQ, Ge FF, Ju HB, et al. Whole-genome analysis of porcine epidemic diarrhea virus (PEDV) from eastern China. Arch Virol. 2014;159(10):2777-2785.

78. Sun M, Ma J, Wang Y, et al. Genomic and epidemiological characteristics provide new insights into the phylogeographical and spatiotemporal spread of porcine epidemic diarrhea virus in Asia. J Clin Microbiol. 2015;53(5):1484-1492.

79. Zhang X, Pan Y, Wang D, Tian X, Song Y, Cao Y. Identification and pathogenicity of a variant porcine epidemic diarrhea virus field strain with reduced virulence. Virol J. 2015;12:88.

80. Suzuki T, Murakami S, Takahashi O, et al. Molecular characterization of pig epidemic diarrhoea viruses isolated in Japan from 2013 to 2014. Infect Genet Evol. 2015;36:363-368.

81. Yamamoto R, Soma J, Nakanishi M, Yamaguchi R, Niinuma S. Isolation and experimental inoculation of an S INDEL strain of porcine epidemic diarrhea virus in Japan. Res Vet Sci. 2015;103:103-106.

82. Murakami S, Miyazaki A, Takahashi O, et al. Complete genome sequence of the porcine epidemic diarrhea virus variant tottori2 JPN/2014. Genome Announc. 2015;3(4):e00877-15.

83. Kim YK, Cho YY, An BH, et al. Molecular characterization of the spike and ORF3 genes of porcine epidemic diarrhea virus in the Philippines. Arch Virol. 2016;161(5):1323-1328.

84. Van Diep N, Norimine J, Sueyoshi M, Lan NT, Hirai T, Yamaguchi R. US-like isolates of porcine epidemic diarrhea virus from Japanese outbreaks between 2013 and 2014. Springerplus. 2015;4:756.

85. Vlasova AN, Marthaler D, Wang Q, et al. Distinct characteristics and complex evolution of PEDV strains, North America, May 2013-February 2014. Emerg Infect Dis. 2014;20(10):1620-1628.

86. Song D, Moon H, Kang B. Porcine epidemic diarrhea: a review of current epidemiology and available vaccines. Clin Exp Vaccine Res. 2015;4(2):166-176.

87. Lowe J, Gauger P, Harmon K, et al. Role of transportation in spread of porcine epidemic diarrhea virus infection, United States. Emerg Infect Dis. 2014;20(5):872-874.

88. Bowman AS, Krogwold RA, Price T, Davis M, Moeller SJ. Investigating the introduction of porcine epidemic diarrhea virus into an Ohio swine operation. BMC Vet Res. 2015;11:38.

89. Sasaki Y, Alvarez J, Sekiguchi S, Sueyoshi M, Otake S, Perez A. Epidemiological factors associated to spread of porcine epidemic diarrhea in Japan. Prev Vet Med. 2016;123:161-167.

90. Pasick J, Berhane Y, Ojkic D, et al. Investigation into the role of potentially contaminated feed as a source of the first-detected outbreaks of porcine epidemic diarrhea in Canada. Transbound Emerg Dis. 2014;61(5):397-410.
91. Opriessnig T, Xiao CT, Gerber PF, Zhang J, Halbur PG. Porcine epidemic diarrhea virus RNA present in commercial spraydried porcine plasma is not infectious to naive pigs. PLoS One. 2014;9(8):e104766.

92. Alonso C, Goede DP, Morrison RB, et al. Evidence of infectivity of airborne porcine epidemic diarrhea virus and detection of airborne viral RNA at long distances from infected herds. Vet Res. 2014;45:73.

93. Beam A, Goede D, Fox A, et al. A porcine epidemic diarrhea virus outbreak in one geographic region of the United States: descriptive epidemiology and investigation of the possibility of airborne virus spread. PLoS One. 2015;10(12):e0144818.

94. Shibata I, Tsuda T, Mori M, Ono M, Sueyoshi M, Uruno K. Isolation of porcine epidemic diarrhea virus in porcine cell cultures and experimental infection of pigs of different ages. Vet Microbiol. 2000;72(3-4):173-182.

95. Martelli P, Lavazza A, Nigrelli AD, Merialdi G, Alborali LG, Pensaert MB. Epidemic of diarrhoea caused by porcine epidemic diarrhoea virus in Italy. Vet Rec. 2008;162(10):307-310.

96. Saif L, Pensaert MB, Sestak K, Yeo SG, Jung K. Coronaviruses. Hoboken, NJ: Wiley-Blackwell; 2012.

97. Moon HW, Norman JO, Lambert G. Age dependent resistance to transmissible gastroenteritis of swine (TGE). I. Clinical signs and some mucosal dimensions in small intestine. Can J Comp Med. 1973;37(2):157-166

98. Bi J, Zeng S, Xiao S, Chen H, Fang L. Complete genome sequence of porcine epidemic diarrhea virus strain AJ1102 isolated from a suckling piglet with acute diarrhea in China. $J$ Virol. 2012;86(19):10910-10911

99. Luo Y, Zhang J, Deng X, Ye Y, Liao M, Fan H. Complete genome sequence of a highly prevalent isolate of porcine epidemic diarrhea virus in South China. J Virol. 2012;86(17):9551.

100. Chen Q, Gauger PC, Stafne MR, et al. Pathogenesis comparison between the United States porcine epidemic diarrhea virus prototype and S-INDEL-variant strains in conventional neonatal piglets. J Gen Virol. Epub February 3, 2016.

101. Jung K, Wang Q, Scheuer KA, Lu Z, Zhang Y, Saif LJ. Pathology of US porcine epidemic diarrhea virus strain PC21A in gnotobiotic pigs. Emerg Infect Dis. 2014;20(4):662-665.

102. Li BX, Ge JW, LiYJ. Porcine aminopeptidase $\mathrm{N}$ is a functional receptor for the PEDV coronavirus. Virology. 2007;365(1):166-172.

103. Park JE, Shin HJ. Porcine epidemic diarrhea virus infects and replicates in porcine alveolar macrophages. Virus Res. 2014;191: 143-152.

104. Gerber PF, Gong Q, Huang YW, Wang C, Holtkamp D, Opriessnig T. Detection of antibodies against porcine epidemic diarrhea virus in serum and colostrum by indirect ELISA. Vet J. 2014;202(1): 33-36.

105. Gerber PF, Opriessnig T. Detection of immunoglobulin (Ig) A antibodies against porcine epidemic diarrhea virus (PEDV) in fecal and serum samples. MethodsX. 2015;2:368-373.

106. Zhang Q, Shi K, Yoo D. Suppression of type I interferon production by porcine epidemic diarrhea virus and degradation of CREB-binding protein by nsp1. Virology. 2016;489:252-268.

107. Xing Y, Chen J, Tu J, et al. The papain-like protease of porcine epidemic diarrhea virus negatively regulates type I interferon pathway by acting as a viral deubiquitinase. J Gen Virol. 2013;94(Pt 7):1554-1567.

108. Cao L, Ge X, Gao Y, et al. Porcine epidemic diarrhea virus inhibits dsRNA-induced interferon-beta production in porcine intestinal epithelial cells by blockade of the RIG-I-mediated pathway. Virol $J$. 2015;12:127.

109. Wang D, Fang L, Shi Y, et al. Porcine epidemic diarrhea virus 3C-like protease regulates its interferon antagonism by cleaving NEMO. J Virol. 2015;90(4):2090-2101.

110. Annamalai T, Saif LJ, Lu Z, Jung K. Age-dependent variation in innate immune responses to porcine epidemic diarrhea virus infection in suckling versus weaned pigs. Vet Immunol Immunopathol. 2015;168(3-4):193-202. 
111. Gao Q, Zhao S, Qin T, Yin Y, Yang Q. Effects of porcine epidemic diarrhea virus on porcine monocyte-derived dendritic cells and intestinal dendritic cells. Vet Microbiol. 2015;179(3-4):131-141.

112. de Arriba ML, Carvajal A, Pozo J, Rubio P. Lymphoproliferative responses and protection in conventional piglets inoculated orally with virulent or attenuated porcine epidemic diarrhoea virus. $J$ Virol Methods. 2002;105(1):37-47.

113. de Arriba ML, Carvajal A, Pozo J, Rubio P. Mucosal and systemic isotype-specific antibody responses and protection in conventional pigs exposed to virulent or attenuated porcine epidemic diarrhoea virus. Vet Immunol Immunopathol. 2002;85(1-2): 85-97.

114. Ouyang K, Shyu DL, Dhakal S, et al. Evaluation of humoral immune status in porcine epidemic diarrhea virus (PEDV) infected sows under field conditions. Vet Res. 2015;46:140.
115. Ayudhya SN, Assavacheep P, Thanawongnuwech R. One world - one health: the threat of emerging swine diseases. An Asian perspective. Transbound Emerg Dis. 2012;59(Suppl 1):9-17.

116. Goede D, Murtaugh MP, Nerem J, Yeske P, Rossow K, Morrison R. Previous infection of sows with a "mild" strain of porcine epidemic diarrhea virus confers protection against infection with a "severe" strain. Vet Microbiol. 2015;176(1-2):161-164.

117. Wang X, Chen J, Shi D, et al. Immunogenicity and antigenic relationships among spike proteins of porcine epidemic diarrhea virus subtypes G1 and G2. Arch Virol. 2016;161(3):537-547.

118. Song DS, Oh JS, Kang BK, et al. Oral efficacy of Vero cell attenuated porcine epidemic diarrhea virus DR13 strain. Res Vet Sci. 2007;82(1):134-140.

\section{Publish your work in this journal}

Virus Adaptation and Treatment is an international, peer-reviewed open access journal focusing on the study of virology, viral adaptation and the development and use of antiviral drugs and vaccines to achieve improved outcomes in infection control and treatment. The journal welcomes original research, basic science, clinical \& epidemiological

\section{Dovepress}

studies, reviews \& evaluations, expert opinion and commentary, case reports and extended reports. The manuscript management system is completely online and includes a very quick and fair peer-review system, which is all easy to use. Visit http://www.dovepress.com/ testimonials.php to read real quotes from published authors. 